\title{
Early Postoperative Fasting Serum Glucose Levels are Useful in Depicting Future Diabetes Mellitus in Patients with Curative Insulinoma Surgery
}

\author{
Authors \\ Aycan Akca1, 2, Achim A. R. Starke², Anna Dobek ${ }^{3}$, Alexis Ulrich³, Peter E. Goretzki², 4
}

Affiliations

1 Department of Endocrine Surgery, Lukaskrankenhaus Neuss, Neuss, Germany

2 Insulinoma and GEP Tumor Center Neuss-Düsseldorf, Lukaskrankenhaus Neuss, Neuss, Germany

3 Department of Visceral Surgery, Lukaskrankenhaus Neuss, Neuss, Germany

4 Department of Endocrine Surgery, Charité Berlin, Germany

Key words

insulinoma, hyperglycemia, postoperative, pancreas function, diabetes mellitus, insulin

$\begin{array}{ll}\text { received } & 19.12 .2018 \\ \text { revised } & 18.03 .2019 \\ \text { accepted } & 05.04 .2019\end{array}$

Bibliography

DOI https://doi.org/10.1055/a-0892-4157

Published online: 30.4 .2019

Exp Clin Endocrinol Diabetes 2020; 128: 158-163

(C) J. A. Barth Verlag in Georg Thieme Verlag KG Stuttgart . New York

ISSN 0947-7349

\section{Correspondence}

Dr. Aycan Akca

Department of Endocrine Surgery,

Lukaskrankenhaus Neuss,

Preussenstraße 84,

41464 Neuss,

Germany

phone: +49-2131-888-3012, fax:+49-2131-888-3095

aakca@lukasneuss.de

\begin{abstract}
Background Hyperglycemia has been reported in some patients after curative insulinoma resection but no systematic investigation of glucose metabolism has been shown in a larger cohort of these patients. Therefore, it is still unknown, whether long lasting hyperinsulinism in insulinoma patients induces insulin resistance, which may jeopardize the postoperative health status of these patients.

Methods Early postoperative fasting serum glucose levels were measured in all insulinoma patients after curative tumor resection during the first $48 \mathrm{~h}$, being operated between 2011 and 2018 , retrospectively.

Results Of 77 (100\%) patients with benign, spontaneous occuring insulinoma 51 (66.2\%) patients were operated on by tumor enucleation. In 15 (19.5\%) patients a left pancreatic resection was performed and in 11 (14.3\%) patients the pancreatic head or the middle console of pancreatic corpus were excised. In 32 (41.6\%) cases the highest fasting postoperative glucose levels were measured between $140-200 \mathrm{mg} / \mathrm{dl}$. In 16 (20.8\%) patients the glucose serum levels reached values above $200 \mathrm{mg} / \mathrm{dl}$ and in 4 (5.2\%) patients short term substitution with insulin was indicated. Only one $(1.3 \%)$ of these patients developed diabetes mellitus with the need of ongoing insulin treatment. Major postoperative complications were registered in 31 of all 77 patients ( $40.3 \%$ ) and in 9 of 16 patients $(56.3 \%)$ with postoperative glucose levels above $200 \mathrm{mg} / \mathrm{dl}$. This difference was not statistically significant.

Conclusions Early postoperative (first $48 \mathrm{~h}$ ) fasting serum glucose levels in insulinoma patients showed significant hyperglycemia above $200 \mathrm{mg} / \mathrm{dl}$ in only few patients (20.8\%) and chronic postoperative Diabetes mellitus developed in only one of 77 patients $(<2 \%)$. Therefore, recovery of glucose metabolism after insulinoma resection is fast and medical intervention is not mandatory in most of these patients.
\end{abstract}

\section{Introduction}

Successful resection of all pathologic pancreatic tissue secreting insulin, such as single adenomas, insulinomatosis or multiple insulinomas can be proven by the rising fasting (without glucose infusion) intraoperative serum glucose levels. It has become a helpful and accepted quality control in insulinoma surgery, nowadays
$[1,2]$. Beside this, the early postoperative glucose metabolism in patients with successfully resected insulinomas has not been subject for systematic investigations, to our knowledge. Only few reports of pathologic postoperative serum glucose levels above $200 \mathrm{mg} / \mathrm{dl}$ and even fewer anecdotal experience with long-term Diabetes mellitus, in these patients, have been published [2,3]. Despite the generally accepted downregulation of insulin receptors 
in patients with pancreatic hyperinsulinism, little is known about the course and length of the altered glucose metabolism in insulinoma patients after curative surgery.

\section{Material and Methods}

\section{Patients}

All patients were included, being operated on for non malignant and non familial insulinoma between January 2001 and March 2018, retrospectively.

\section{Preoperative diagnosis}

Preoperative diagnosis of insulinoma included biochemical determination of venous blood glucose levels $<40 \mathrm{mg} / \mathrm{dl}$ and measurable insulin levels or proinsulin levels of $>3 \mathrm{mlU} / \mathrm{l}$ or $>2 \mathrm{pmol} / \mathrm{l}$, respectively and a measurable $C$-peptide at time of symptoms. The reference values for glucose levels is $75-110 \mathrm{mg} / \mathrm{dl}$ in our hospital. Symptoms resolved after glucose intake (Whipple triad). An oral glucose tolerance test was performed in almost all patients. At least in all patients with questionably proven spontaneous hypoglycemia and hyperinsulinemia, > Fig. 1. None of the patients suffered from Diabetes mellitus, preoperatively. For localisation studies endosonography, CT and/or MRI were used.

\section{Surgical treatment of insulinoma}

Depending on the localisation and size of the insulinoma an enucleation, pancreatic left sided resection or a pylorus preserving pancreatoduodenal resection (PPPD) was performed, > Table 1.
In all patients a drainage was inserted, which was removed when amylase levels dropped below $150 \mathrm{ml}$. Hospital and 30 days mortality was measured as well as all postoperative complications, including pancreatic fistula grads (A-C), bleeding, postoperative reintervention and secondary wound healing

\section{Intra- and postoperative serum glucose levels}

Intraoperative glucose levels ( $\mathrm{mg} / \mathrm{dl}$ ) were controlled prior to anesthesia and at least three times during the operation. The reference values for glucose levels is $75-110 \mathrm{mg} / \mathrm{dl}$ in our hospital. No glucose infusion was given and surgery was only terminated, when an adequate neuroendocrine tumor was found and resected, and when serum glucose levels increased after tumor resection for at least $20-30 \mathrm{mg} / \mathrm{dl}$, additionally.

To investigate spontaneous postoperative glucose metabolism in these patients we routinely restrained from intra- and postoperative glucose substitution and measured spontaneous fasting serum glucose levels for $48 \mathrm{~h}$. Thus, patients adequately substituted with electrolytes and fluids did not get any caloric infusion nor any oral calories for the first and second postoperative day. Serum Glucose levels were measured every $4 \mathrm{~h}$, at least, to determine, whether hyperglycemia by an ongoing down-regulation of insulin receptor activity occurs, or, whether recovery of this postoperative hyperglycemia might be fast with no need of medical intervention, such as insulin substitution.

\section{Postoperative complications}

All patients received a drainage, which remained until suspension of high amylase fluid secretion.
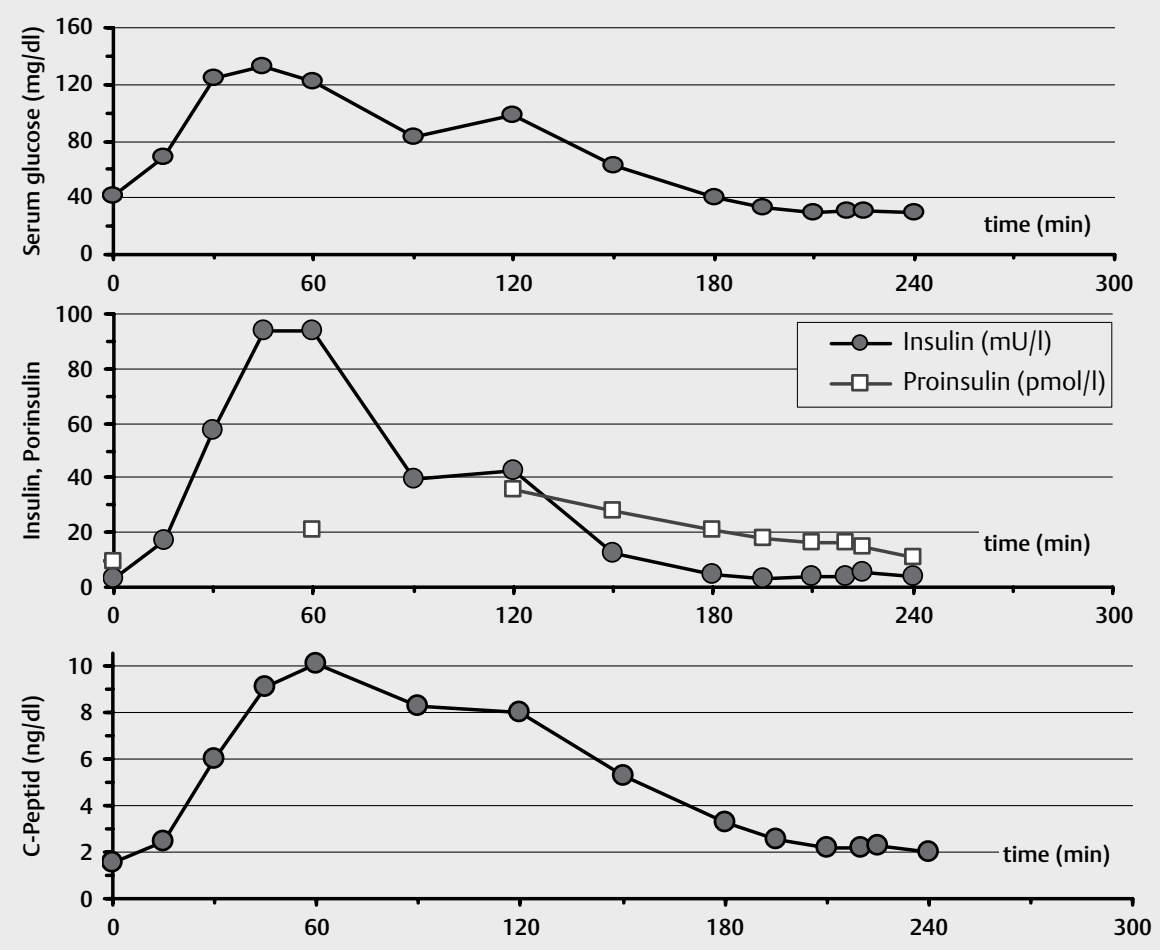

- Fig. 1 OGTT-fasting test in one of the patients: Termination of the test after 3 hours because of neuroglycopenia with somnolence and dizziness, blood glucose $30-33 \mathrm{mg} / \mathrm{dl}$, Insulin $3.1-5.7 \mathrm{mU} / \mathrm{l}$ and Proinsulin 11-18 pmol/l. 
- Table 1 Follow-up of postoperative serum glucose.

\begin{tabular}{|c|c|c|c|c|c|c|c|}
\hline Operation & $\begin{array}{l}\text { Glc (mg/dl) 24-48h } \\
\text { pop N (\%) }\end{array}$ & $<140$ & $140-200$ & $>200$ & Unknown & $\begin{array}{l}\text { Insulin } \\
\text { therapy }\end{array}$ & $\begin{array}{l}\text { Diabetes } \\
\text { Mellitus }\end{array}$ \\
\hline Enucleation & $50(64.9)$ & $18(36)$ & $22(44)$ & $9(18)$ & $1(2)$ & $1(2)$ & \\
\hline Left Resection & $16(20.8)$ & $6(37.5)$ & $5(31.3)$ & $4(25)$ & $1(6.3)$ & $2(12.5)$ & $1(6.3)$ \\
\hline Segment & $3(3.9)$ & $1(33.3)$ & $1(33.3)$ & $1(33.3)$ & & $1(33.3)$ & \\
\hline Traverso & $8(10.4)$ & & $4(50)$ & $2(25)$ & $2(25)$ & & \\
\hline Total & $77(100)$ & $25(32.4)$ & $32(41.6)$ & $16(20.8)$ & $4(5.2)$ & $4(5.2)$ & $1(1.3)$ \\
\hline
\end{tabular}

- Table 2 Complications and hyperglycemia after resection.

\begin{tabular}{|l|l|l|l|l|l|}
\hline Patient & Gender & Age & Operation & Postoperative complications & Diabetes mellitus \\
\hline M.P. & M & 30 & Segmental resection & Pancreatitis Pneumonia Pancreatic fistula & No \\
\hline G.O. & M & 28 & Left-resection & Pancreatic fistula & Yes \\
\hline R.G. & F & 57 & Left-resection & Pancreatitis & No \\
\hline J.G. & F & 59 & Enucleation & Pancreatic fistula & No \\
\hline F: female, M: male, Left: $60 \%$ distal pancreatectomy.
\end{tabular}

F: female, M: male, Left: $60 \%$ distal pancreatectomy.

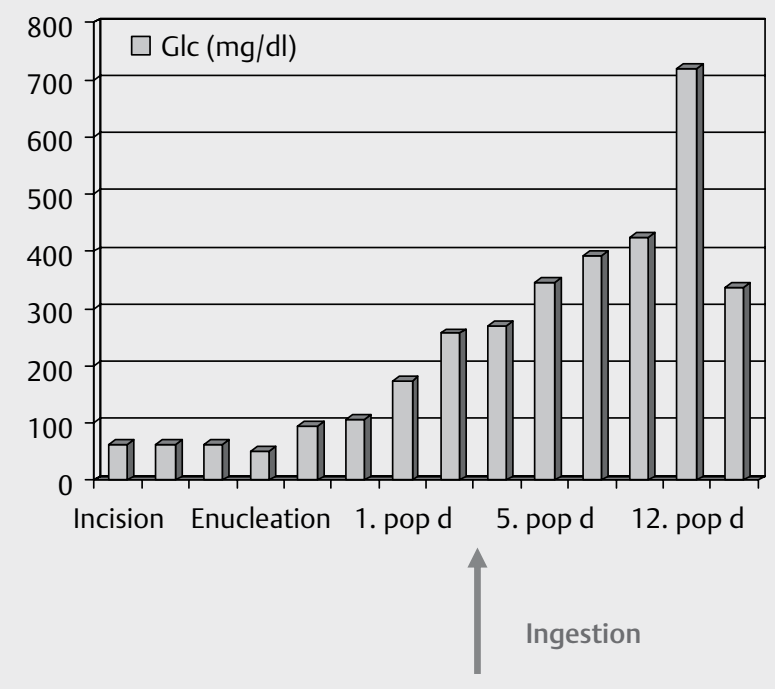

- Fig. 2 Follow-up of serum glucose after insulinoma resection in a patient with diabetes mellitus.

Pancreatic fistulas were primarily treated conservatively, either by leaving the intraoperatively drainage or by inserted a new CTguided drainage. Pancreatic fistulas were defined using the classification of ISGPF, claiming a 3-fold increase in amylase concentration of the drained secretion compared to the serum amylase at the third postoperative day. Clinically, three levels of pancreatic fistulas were differentiated, A, B and C as defined by Bassi et al. [4].

\section{Results}

From 2001 to 2018, 286 patients with neuroendocrine neoplasia (NEN) were diagnosed and treated in our department. 87 patients (30.4\%) were diagnosed with pancreatogenic hypoglycemia, 10 patients $(11.5 \%)$ of those had a malignant insulinoma and they were excluded from this study. None of the patients had a diabetes mellitus preoperativly.

$52(67.5 \%)$ of 77 patients were female and 25 (32.5\%) were male. The median age at time of operation was 49.9 years ( $21-76$ years).

In 51 (66.2\%) patients an enucleation was performed, 15(19.5\%) underwent a distal pancreatectomy, $8(10.4 \%)$ a pylorus preserving pancreatoduodenectomy (PPPD) and 3 patients (3.9\%) underwent a segmental middle resection of the pancreas, respectively.

The median hospital stay was 15.5 days (4-33 days).

\section{Postoperative follow-up}

In 25 cases (32.4\%) spontaneous postoperative serum glucose levels $<140 \mathrm{mg} / \mathrm{dl}$ were measured and in 32 cases $(41.6 \%$ ) it varied between 140 and $200 \mathrm{mg} / \mathrm{dl}$ during the first $48 \mathrm{~h}$. In 16 (20.8\%) patients the serum glucose value reached levels $>200 \mathrm{mg} / \mathrm{dl}$, > Table 1. Four (5.2\%) of these patients needed postoperative insulin therapy, but only 1 (1.3\%) developed long-term diabetes mellitus, - Table 1 and $\checkmark \mathbf{2}$, Fig. $\mathbf{2}$ and $>$ Fig. 3 . The other 3 patients needed only one or two doses of insulin.

46 of 77 patients $(59.7 \%)$ had no postoperative complications. 12 patients (15.6\%) developed pancreatic fistulas (type A-B) postoperatively, which were successfully treated by drainage and antibiotics without further operation, needed. One patient (1.3\%) developed a grade $C$ fistula with colon fistula. A left hemicolectomy was performed. 7 patients ( $9.1 \%$ ) developed pancreatitis, two patients $(2.6 \%)$ a pseudo cyst and 6 patients $(7.8 \%)$ had a postoperative bleeding. 8 patients (10.4\%) suffered from non-pancreatic complications, such as pneumonia $(n=5)$ and myocardial infarction $(n=3)$, respectively. There was no death during the hospital stay and within 90 days postoperatively.

Comparing the complication rate of all patients ( $31 / 77=40.3 \%)$ with this of 16 patients with postoperative glucose levels above $200 \mathrm{mg} / \mathrm{dl}(9 / 16=56.3 \%)$ there was no statistically significant difference, detectable (Chi-square test). 

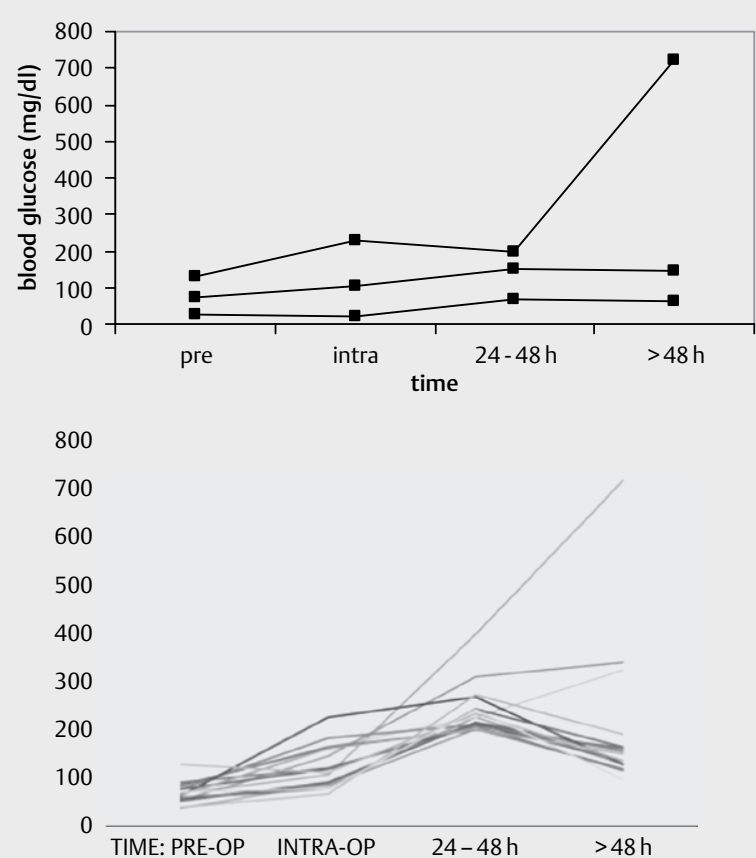

- Fig. 3 Follow-up of serum glucose after insulinoma resection in all patients (upper limit, mean and lower value) a (mean + deviation) and every single patient $\mathbf{b}$ with blood glucose $>200 \mathrm{mg} / \mathrm{dl}$.

\section{Long-term follow-up}

One year later all patients were subsequently contacted and questioned, but only one patient (1.3\%) developed Diabetes mellitus within 12 months after left pancreatic resection, > Table 2. His $\mathrm{HbA} 1 \mathrm{c}$ was $7.9 \%$ under treatment with insulin and metformin.

\section{Follow-up in 4 patients with severe postoperative hyperglycemia, > Table 2}

\section{Case 1}

A 30-year-old male patient underwent a segmental resection of the pancreas. Within the first $48 \mathrm{~h}$ the patient developed hyperglycemia with values $>300 \mathrm{mg} / \mathrm{dl}$. On the second postoperative day he developed increased temperatures with increased serum lipase and leucocytosis. A thorax X-ray showed pneumonia in the left lung lobe. After starting an antibiotic therapy the inflammatory markers as well as lipase decreased. The increased glucose levels could be well managed with insulin therapy, so that the treatment could be stopped soon. Blood glucose was $138-163 \mathrm{mg} / \mathrm{dl}$.

\section{Case 2}

A 28-year-old male patient, who had undergone surgery showed a rapid postoperative increase of blood glucose $(>300-700 \mathrm{mg} / \mathrm{dl}$ ) and he developed a pancreatic fistula on postoperative day 6 . High blood glucose levels continued to rise, consequently developing diabetes mellitus (HbA1c 7.9\%) and the patient needed insulin therapy (BG 200-400 mg/dl), > Fig. 2.

\section{Case 3}

A 57-year-old female patient underwent a left resection and developed consecutive pancreatitis. Because of the elevated blood glucose levels ( $>335 \mathrm{mg} / \mathrm{dl}$ ) the patient received insulin for short time.

\section{Case 4}

In a 59-year-old female an enucleation of the insulinoma was performed. She developed a pancreatic fistula. After hyperglycemia with values around $325 \mathrm{mg} / \mathrm{dl}$ the patient received a single insulin dose, consequently the hyperglycaemia regressed permanently.

\section{Discussion}

Monitoring intra- and postoperative glucose serum levels serves as quality control in operative treatment of insulinoma, malignant insulinoma, NIPHS and MEN I. Prior to resection of insulinoma blood glucose levels may decrease significantly and after successful resection of the tumor blood glucose levels usually rise quite fast, sometimes even above normal serum levels (hyperglycemic rebound) $[1,2]$. Some authors reported postoperative blood glucose levels up to 200 to $400 \mathrm{mg} / \mathrm{dl}$ in between the following next hours, which were treated with insulin perfusion [2]. But nobody systematically analysed, whether postoperative deterioration of glucose metabolism after successful insulinoma resection recovers fast or may require insulin therapy in a certain percentage of these patients.

Prevention of hyperglycemia during and after pancreatic surgery in insulinoma patients is thought to be as important as prevention of hypoglycaemia, preoperatively. Accepted factors inducing postoperative hyperglycemia are the insulin resistance after long-standing hyperinsulinism, the reduction of pancreatic parenchyma with reduced numbers of islets, and the stress as well as other factors causing hyperglycemia even in patients with normal insulin secretion and glucose metabolism [5-7]. Present literature describes early postoperative hyperglycemia ("inadequate glucose metabolism or early postoperative pancreatogenic diabetes mellitus") in $8-23 \%$ of patients after successful insulinoma operations, depending on the extent of pancreatic resection. Our systematic measurements demonstrated spontaneous serum glucose levels between $140-200 \mathrm{mg} / \mathrm{dl}$ in 32 of 77 patients (41.6\%) and serum glucose levels above $200 \mathrm{mg} / \mathrm{dl}$ in 16 of 77 patients (20.8\%). Thus we show that pathologically functioning early postoperative glucose metabolism may lead to spontaneous serum glucose levels above $200 \mathrm{mg} / \mathrm{dl}$ in more than half of all patients after insulinoma surgery.

To avoid hyperglycemia or hypoglycemia some authors even use an artificial endocrine pancreas or continuous glucose infusion to control blood glucose concentration in patients with insulinoma during and after insulinoma resection $[9,11,12]$.

We, however, did not correct serum glucose levels between the margines of $20-250 \mathrm{mg} / \mathrm{dl}$, perioperatively. We accepted low serum glucose levels as low as $20 \mathrm{mg} / \mathrm{dl}$ during surgery to be able to see the fast increase of serum glucose after tumor resection, and to use this as an important intraoperative quality control. No ceisure or other negative pathophysiologic effect was present in our patients with low serum levels up to $20 \mathrm{mg} / \mathrm{dl}$. Neither we corrected spontaneous serum glucose levels postoperatively during the first $48 \mathrm{~h}$ after surgery up to a value of $250 \mathrm{mg} / \mathrm{dl}$. Patients were al- 
lowed unrestricted fluid intake, were supported with adequate i.v. infusion of electrolytes and fluid but without glucose or any other caloric substitution.

Spontaneous direct increase of serum glucose after insulinoma resection thus verified the surgical success and the level of postoperative hyperglycemic during the first $48 \mathrm{~h}$, and gave us an estimate for recovery of long-term glucose metabolism. Administration of insulin was accepted, however, at a value about $250 \mathrm{mg} / \mathrm{dl}$. We observed that only four patients developed these high serum glucose levels and treated with insulin, but just for a short time. In fact, only one patient $(1.3 \%)$ developed diabetes mellitus indicating that function of the remaining tissue recovers fast and that downregulation of insulin receptors may persist for only a very short while.

Our results also show that complications in patients with inadequate high serum glucose levels during the first $48 \mathrm{~h}$, postoperatively, are not increased, when compared to patients demonstrating serum glucose levels below $200 \mathrm{mg} / \mathrm{dl}$. Therefore, medical intervention such as insulin infusion or even use of an artificial pancreas is not mandatory in most of these patients.

Of course we don't know, whether patients with postoperative serum glucose levels above $200 \mathrm{mg} / \mathrm{dl}$ may have an increased risk of developing type 2 diabetes in the following years as it has been shown for women with gestational diabetes [13]. The risk of developing diabetes mellitus in between the next $5-10$ years is sevenfold higher in women with gestational diabetes than in other pregnant women, as shown by Baeyens et al. [13]. It also is unknown how glucose metabolism in pregnant women changes during and after resection of an insulinoma. Interaction between different cells like placental lactogen and ß-cells, as well as ß-cell adaptation has been shown in pregnancy, but final answers are still lacking [13].

Results of long-term postoperative follow-up will also have to be evaluated in our patients, to prove, whether spontaneous postoperative glucose levels up to $200 \mathrm{mg} / \mathrm{dl}$ may have any prognostic impact on future glucose metabolism, when compared to patients with lower postoperative serum glucose levels.

Beside these problems in regulatory adaption of glucose metabolism also permanent postoperative diabetes mellitus has been shown by some authors in patients with successful insulinoma resection $[8,9]$. Some of these patients have suffered from a coexisting diabetes mellitus [10] and it occurred that diabetes mellitus was only masked by the activity of an insulinoma. In these patients the prior illness of diabetes mellitus manifested again after resection of the insulin producing tumor [3]. In some rare cases with persisting diabetes mellitus, however, no history of prior diabetes mellitus was evident, as it was not in the only one of our 77 patients $(1.3 \%)$ with permanent diabetes mellitus. The accepted cause of diabetes mellitus in these patients may be explained by the wide excision of functional islets during tumor resection with reduction of islet cells below a critical mass. This is in accordance with retrospective analyses in insulinoma patients that show diabetes mellitus more often in patients after insulinoma surgery when pancreatic resection has been performed than after enucleation of tumor tissue, only [3].

Our experience parallels these data. Enucleation and additional pancreatic tissue resection were followed by normal spontaneous postoperative glucose serum levels in 18 of 50 patients (36\%) and
6 of 27 patients (26\%) as spontaneous postoperative hyperglycemia above $200 \mathrm{~m} / \mathrm{dl}$ occurred 9 of 50 patients (18\%) after enucleation and in 7 of 27 patients ( $26 \%$ ) after additional pancreatic tissue resection. The trend of impaired postoperative glucose metabolism therefore parallels additional normal tissue resection.

The only patient in these 77 patients with insulinoma, developing postoperative diabetes mellitus showed spontaneous early postoperative serum glucose levels above $200 \mathrm{mg} / \mathrm{dl}$. Measuring spontaneous early postoperative serum glucose levels might be helpful, therefore, to depict patients at risk for postoperative diabetes mellitus, especially when resection of normal pancreatic tissue was needed.

\section{Conclusion}

Our results in 16 (20.8\%) patients with insulinoma showed that significant hyperglycaemia occurred only in few patients. Therefore we can conclude that the beta cell adaptation after insulinoma resection is fast, hyperglycemia after insulinoma resection seems to be a rare problem indicating diabetes mellitus, but could be useful in depicting future diabetes mellitus with curative insulinoma surgery.

\section{Conflict of Interest}

The authors declare that they have no conflict of interest.

\section{References}

[1] Van Heerden JA, Edis AJ, Service FJ. The surgical aspects of insulinoma. Ann Surg 1979; 189: 677-682

[2] Mehrabi A, Fischer L, Hafezi M et al. A systemic review of localization, surgical treatment options, and outcome of insulinoma. Pancreas 2014; Vol 43: Number 5 675-686

[3] Ahn J, Lee SE, Choi YS et al. Overtly manifested Diabetes Mellitus after resection of insulinoma. Inter Med 2009; 48: 2105-2107

[4] Bassi C, Dervenis C, Butturini G et al. Postoperative pancreatic fistula: An international study group (ISGPF) definition. Surgery 2005; 138 : 8-13. doi:10.1016/j.surg.2005.05.001

[5] WHO (World Health Organization), Department of Noncommunicable Disease Surveillance. Definition, Diagnosis and Classification of Diabetes Mellitus and Complications. 1999 WHO/NCD/NCS/99.2;

[6] Haller N. Diabetes mellitus Typ III Deutsches Zentrum für Diabetes Forschung. Crossmed 2013

[7] Nauck M, Petermann A, Müller-Wieland D et al. Definition, Klassifikation und Diagnostik des Diabetes Mellitus. Diabetologie 2017; 12: (Suppl 2): S94-S100

[8] Nikfarjam M, Warshaw AL, Axelrod L et al. Improved contemporary surgical management of insulinomas: a 25-year experience at the Massachusetts General Hospital. Annals of Surgery 2008; 247: 165-172

[9] Hirose K, Kawahito S, Mita $\mathrm{N}$ et al. Usefulness of artifical endocrine pancreas during resection of insulinoma. Journal of Medical Investigation 2014; Vol 61: 421-425

[10] Kamocki ZK, Wodynska NA, Pryczynicz A. Co-existence of insuinoma and diabetes: a case report. Oncology letters 2014; 8: 1697-1700 
[11] Nishida K, Shimoda S, Ichinose $K$ et al. What is artificial endocrine pancreas? Mechanism and history. WJG 2009; 15: 4105-4110

[12] Muir J], Endres SM, Offord K et al. Glucose management in patients undergoing operation for insulinoma removal. Anesthesiology 1983; 59: $371-375$
[13] Baeyens L, Hindi S, Dorenson RL et al. ß-cell adaptation in pregnancy. Diabetes Obes Metab 2016; 18: (Suppl 1): 63-70 